CASE REPORTS

\title{
GIANT CELL ARTERITIS WITH ANEURYSMAL FORMATION IN AN INFANT
}

\author{
BY
}

\author{
MICHAEL GELFAND
}

\author{
From Salisbury Native Hospital, S. Rhodesia
}

As an aneurysm is rare in infancy or childhood, it is considered of interest to publish the following details of a case in which it appeared macroscopically to be syphilitic, but histologically proved similar to the condition described as " giant cell arteritis."

\section{Case Report}

The patient was a male (Mashona) African aged about two years. He was carried into hospital on October 16,1950 , by his mother who stated that ten days previously he had begun to experience difficulty in breathing. He had become progressively worse, alarmingly so on the day that his mother sought help at the hospital.

On examination the patient was a well nourished, healthy looking male infant who was struggling for breath and finding expiration more difficult. The temperature was $98^{\circ} \mathrm{F}$. and the pulse rate 130 a minute. The lips and tongue were intensely cyanosed and the eyes congested with a serous discharge issuing from both. No obvious obstruction could be seen on inspection of the glottis and pharynx. The neck veins were distended and the head thrown back but no cervical lymphadenopathy was noted.

Respiration was grunting in type and this made examination of the chest difficult. No adventitious sounds were detected and dullness was not apparent. The apex beat was palpable $1 \mathrm{~cm}$. beyond the left nipple line. The heart rate was 130 a minute and the sinus rhythm was interrupted by short periods of irregularity. The liver edge was barely palpable and the spleen could not be felt. The child was semi-conscious but no abnormality in the central nervous system was detected. A radiograph of the chest revealed the presence of a large mass in the superior mediastinum which extended into the lung fields on both sides, but more prominently into the right upper zone. The rest of the lung fields were clear (Fig. 1). The "tumour" was considered to be a thymoma.

The patient died a few hours after admission.

\section{Necropsy Report}

The subject was a healthy looking child of about two years with thin arms and legs. The brain showed moderate congestion of vessels. The tonsils were enlarged and inflamed and the lungs broncho-pneumonic. A slight hilar adenitis was present. Both ventricles of the heart were moderately dilated, the right ventricle showing a moderate degree of hypertrophy. All the valves were normal. The aorta was normal for the first $6 \mathrm{~cm}$., after which it showed a fusiform dilatation for about $15 \mathrm{~cm}$. of its length associated with wellmarked longitudinal puckering of the intima and thickening. There was no evidence of atheroma macroscopically, but there was a superficial patchy ulceration. The abdominal aorta had the same scarring extending to just below the origin of the superior mesenteric artery. The right subclavian artery was dilated and contained an organizing thrombus. The aneurysm measured $3.3 \times 2.5 \mathrm{~cm}$. All other vessels appeared normal. The liver was congested and the spleen moderately large. Mesenteric adenitis was conspicuous. All other organs were within normal limits.

Histology. The intima of the aorta was thickened owing to the laying down of fine collagen fibres and a fibroblastic proliferation. The internal elastic lamina was completely destroyed in parts. There was a moderate plasma cell and lymphocytic infiltration but no thrombus. The media showed almost complete destruction 


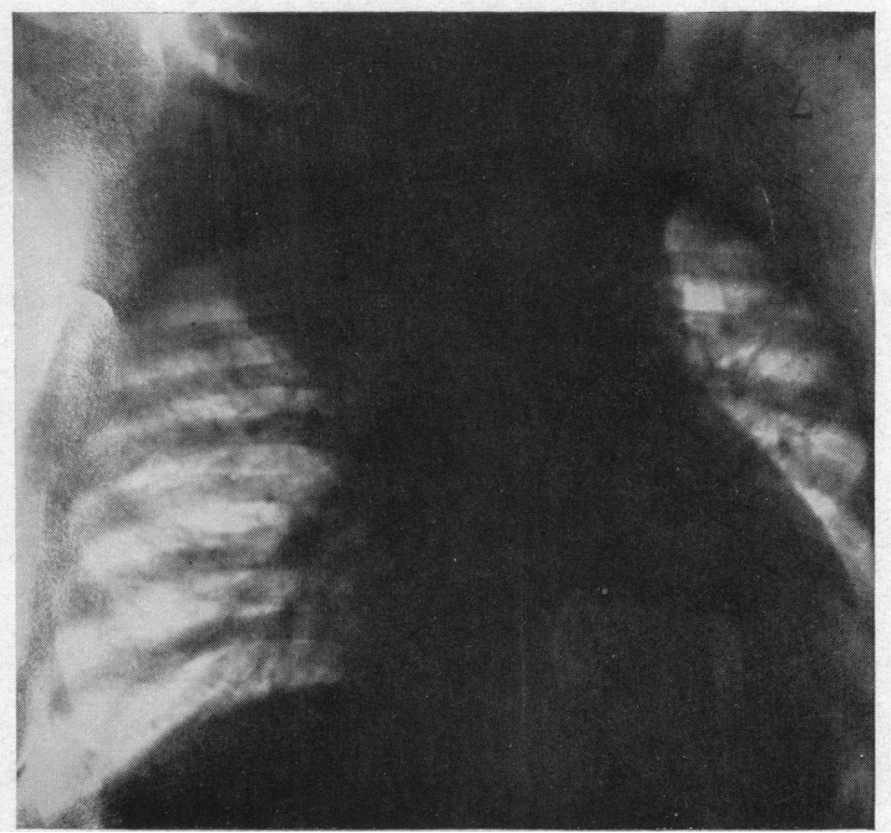

FIG. 1.-X-ray of chest showing density in superior mediastinum, mainly on the right, due to fusiform aneurysm of ascending and descending aorta and right subclavian artery.

of the entire elastic tissue with a fibroblastic proliferation and its replacement by collagen fibres. There was a patchy infiltration of the media by polymorphonuclear leucocytes, plasma cells and lymphocytes which, in some parts, were associated with variously shaped and sized giant cells. Some of these had their nuclei placed circumferentially while in others the nuclei were aggregated together. There was no sign of caseation or necrosis. The inflammatory reaction was mainly in the central part of the media. The adventitia showed fibrosis. The process was a gradually developing one when sections of normal to abnormal aorta were examined, the earliest change appearing to be a leucocytic infiltration of the intima and media. Sections of the subclavian aneurysm were identical histologically.

The anterior descending branch of the left coronary artery showed intimal thickening (localized and irregular) due to the laying down of fine collagen fibres with destruction of the internal elastic lamina but with little evidence of inflammation. The lungs were affected with a non-tuberculous broncho-pneumonia. The myocardium revealed no evidence of Aschoffs' nodules. The liver showed a severe passive venous congestion with no evidence of congenital syphilis. The kidneys appeared to be within normal limits.

No spirochætes or tubercle bacilli were discovered in sections, and smears from the lungs showed no tubercle bacilli.

Cause of death. Asphyxiation due to aneurysm of the aorta and of the right subclavian artery with bronchopneumonia.

\section{Discussion}

Calvin and Nichamin (1934) list the causes of aortic aneurysms in children as follows: (i) atheromatous degeneration; (ii) trauma; (iii) erosion of aorta from without; (iv) congenital malformation; and (v) acute infectious diseases-especially rheumatic fever.

Aneurysms in children have been described in the left renal artery by Howard et al. (1940) in a child of five years suffering from essential hypertension; of the pulmonary artery in a girl, aged twelve years, by Hartwell and Tilder (1943) and in the thoracic aorta in a boy of four and a half years, by Bronson and Sutherland (1928). Calvin and Nichamin (1934) found an aortic aneurysm in two patients with lesions which, prior to death, were regarded as rheumatic; the first was in 
an eleven-year-old child with coarctation of the aorta and the second in a child of four years with an aneurysm of the abdominal aorta in whom no evidence of arteriosclerosis or specific pathology was found.

The ætiology of the arteritis and aneurysm in our patient appears to be different from the causes just quoted. There was no evidence histologically of atheroma, syphilis, rheumatic fever or tuberculosis, which were features of previously reported cases. The histological changes found in the present case appear to conform to those usual in " giant cell arteritis." Gilmour (1941) introduced this term to denote a condition that is similar histologically to "temporal arteritis." Giant-cell arteritis may affect many arteries in a wide-spread manner. In an affected vessel there is intimal thickening without thrombus owing to an increase in cellular fibrous tissue and infiltration with macrophages and lymphocytes and to a lesser degree with plasma cells. The line of demarcation from the media is indistinct, large segments of the internal elastic lamina being destroyed. The maximal lesion is seen in the media. Of interest, too, are the areas of coagulative necrosis and a heavy cellular infiltration similar to that found in the intima. Multinucleated giant cells of both the foreign body and Langhans types are characteristically present. The adventitia shows a cellular infiltration similar to that of the media but to a lesser extent, and without giant cells. In most cases a varying degree of atheroma is also present in the artery. Aneurysm formation, too, has been described in giant cell arteritis. McMillan (1950) has reported two cases of aneurysm formation of the aorta and Gilmour (1941) recorded a death from rupture of an aneurysm of an affected subclavian artery.

Giant-cell arteritis usually occurs in adults over the age of 40 . In nearly all instances so far reported symptoms suggesting an infection had been observed some weeks or months before manifestations of the arteritis developed. The disease may be self-limited, healing after a few weeks or months. In fatal cases, however, death is either from the indirect effects of the arteritis or from independent causes.

The case reported in the present paper differs from the above mainly on the grounds of age and the absence of atheroma.

\section{Summary}

An account is given of the clinical, post-mortem, and histological features of giant-cell arteritis in an African male infant, aged two years. The disease produced a fusiform aneurysm of the right subclavian artery with dilatation of the ascending and descending aorta. No evidence of syphilis, tuberculosis, rheumatic fever, or atheroma was discovered.

I wish to thank Dr. G. Blaine for the pathological and histological reports on the case, and Dr. R. M. Morris, O.B.E., for his permission to publish this paper.

\section{REFERENCES}

Bronson, E., and Sutherland, G. A. (1928). Brit. J. Child. Dis., 15, 16.

Calvin, J. K., and Nichamin, S. J. (1934). Amer. J. Dis. Child., 48, 780.

Gibson, T. A. (1945). Amer. J. Dis. Child., 70, 654.

Gilmour, J. R. (1941). J. Path. Bact., 53, 263.

Hartwell, A. S., and Tilder, I. L. (1943). Amer. Heart J., 26, 692.

Howard, T. L., Forbes, R. P., and Lipscomb, W. R. (1940). Jour. Urol., 44, 808.

McMillan, G. C. (1950). Arch. Path., 49, 63.

Sutherland, G. A. (1923). Brit. J. Child. Dis., $20,27$. 